\title{
Razão e emoção: o voto na \\ eleição presidencial de 2006
}

\author{
Jairo Tadeu Pires Pimentel Junior \\ Programa de Doutorado em Ciência Política \\ Universidade de São Paulo
}

\begin{abstract}
Resumo: Este artigo tem como proposta analisar o papel dos sentimentos na estruturação das escolhas eleitorais durante a eleição presidencial brasileira de 2006. Especificamente, analisa de que forma as emoções dos eleitores em relação aos candidatos afetam e estimulam a avaliação e o voto nos mesmos. Primeiramente, buscamos demonstrar formas de mensuração das emoções em termos quantitativos através de surveys realizados durante o período eleitoral. Em segundo lugar, buscamos evidenciar que a avaliação retrospectiva pode ser mais bem entendida se compreendermos como a avaliação de governo interage com os estados emocionais dos eleitores. Destarte, negando a longa tradição que contrapõe razão e emoção dentro da política, salientamos a tese de que os sentimentos constituem uma importante variável no processamento de informações e, consequentemente, na decisão do voto.
\end{abstract}

Palavras-chave: comportamento eleitoral; voto racional; voto emocional; psicologia política

\begin{abstract}
This article to analyzes the role of emotion in the electoral choices during the 2006 Brazilian presidential election. Specifically, it analyzes in which way the emotions of the voters in relation to the candidates affect and stimulates the evaluation and the vote for them. In the first place, we demonstrate forms of measuring emotions in quantitative terms through surveys conducted during the electoral period. Second, we demonstrate that the retrospective evaluation government's can better be understood if we comprehend in which way the government's evaluation interacts with emotional states of the voters. Thus, denying the long tradition that opposes reason and emotion in politics, we point out the thesis that feelings constitute an important variable in the information processing and, consequently, in the vote decision.
\end{abstract}

Keywords: electoral behavior; rational vote; emotional vote; political psychology 


\section{Introdução ${ }^{1}$}

A ideia de que as emoções estimulam comportamentos políticos não é nova. Já na Antiguidade, tal como argumenta Aristóteles (1959), os oradores sensibilizavam as multidões utilizando um tipo de retórica carregada de sentimentos, denominada pathos. No século XV, Maquiavel (2001) buscou demonstrar aos príncipes não somente a importância de ser amado pelos súditos, mas principalmente temê-los. Weber (1991) chamou de carisma a capacidade de dominação política por meio de atributos inerentes e excepcionais que estimulam a adoração às lideranças políticas. Mais recentemente, na era da mídia eletrônica, vários trabalhos emergiram com a intenção de demonstrar o impacto dos apelos afetivos inerentes às campanhas políticas (SCHWARTZENBERG, 1979; SULLIVAN \& MASTER, 1987, SILVEIRA, 2000; WESTEN, 2007; BRADER, 2007).

Apesar da inegável importância das emoções dentro da história do pensamento político, causa estranheza o fato de elas serem relegadas ao segundo plano na análise empírica da tomada de decisão. Isso pode ser explicado, tal como sustenta Marcus (2003), devido à crença de que as emoções são antagônicas à racionalidade. Trata-se, segundo esse autor, de uma longa tradição normativa dentro do pensamento ocidental que demoniza os impulsos emotivos e busca execrá-los do mundo político por conta de seu potencial destrutivo na tomada de decisões lúcidas, dada a crença em um papel depreciativo dos sentimentos na construção de decisões racionais dentro da esfera pública.

Não obstante essa depreciação dos sentimentos, uma considerável parcela da psicologia política vem tratando de analisar de maneira parcimoniosa o impacto das emoções dentro do processo de tomada de decisão. Tal literatura está particularmente interessada em entender como as emoções estão entrelaçadas com a razão e, nesse sentido, compreender de que forma a convergência entre esses dois fatores produz comportamentos políticos. Nessa literatura, portanto, as emoções não estão separadas da mente, mas sim constituem um importante arranjo no processo cognitivo.

O objetivo deste artigo é analisar o impacto das emoções no voto do eleitor brasileiro, tema muito salientado pelo meio acadêmico, marketing e jornalismo, mas pouco analisado por instrumentos empíricos em nosso contexto. Com este artigo, busca-se trazer à discussão dois elementos para fomentar o debate sobre esse tema no Brasil: em primeiro lugar, demonstrar como as emoções são

\footnotetext{
${ }^{1}$ Este artigo é uma versão de minha Dissertação de Mestrado: Razão e Emoção no Voto, o caso da eleição presidencial de 2006, defendida no Departamento de Ciência Política da USP em 2007 e que recebeu menção honrosa no concurso de teses da ANPOCS em 2008. Ele foi orientado pela Prof. ${ }^{a}$ Maria D'Alva Kinzo, um exemplo de acadêmica e de pessoa, a quem agradeço pelo acolhimento, dedicação e confiança.
} 
estruturadas e como podem ser mensuradas através de pesquisas de surveys. Tratase basicamente de validar as ferramentas quantitativas utilizadas para mensurar as emoções dos eleitores no Brasil, tendo como parâmetro aquelas utilizadas por estudos contemporâneos feitos nos Estados Unidos, de forma a replicar os resultados das medidas emocionais feitas originalmente por pesquisas acadêmicas americanas.

Em segundo lugar, através dos dados coletados, demonstrar a validade de um modelo teórico que versa sobre a relação entre emoção e razão. Em ambos os casos, a principal obra de referência será o livro de Marcus et al, (2000).

Baseado na psicologia das emoções e em aspectos da neurociência, o modelo de Inteligência Afetiva argumenta que o comportamento dos eleitores é guiado por dois tipos de sistemas emocionais que atuam de maneira independente. O primeiro deles, o sistema de predisposição, engendra sentimentos de entusiasmo, e o segundo, o sistema de vigilância, engendra sentimentos de ansiedade. Segundo o argumento desse modelo, esses sentimentos regulam a motivação dos eleitores e servem para indicar quando eles devem manter determinada predisposição em votar em determinado candidato e quando eles devem refletir melhor sobre em quem votar.

Seguindo a tese de Inteligência Afetiva de que razão e emoção se entrelaçam no processamento de informações, este artigo demonstra como os sentimentos engendrados pelos candidatos podem afetar certas considerações racionais e para isso, analisa dois aspectos da decisão eleitoral: o tempo dessa decisão $\boldsymbol{e}$ a mudança no voto.

As hipóteses aventadas são de que eleitores mais entusiasmados pelo governante tendem a decidir mais cedo em quem votar, enquanto que eleitores mais ansiosos tendem a decidir mais tardiamente. Além disso, aponta que fatores de curto prazo que geram ansiedade nos eleitores comprometem a disposição dos eleitores em votarem no governante e podem fazê-los mudar seu voto.

O foco da análise é o caso específico da eleição presidencial de 2006. Essa eleição é marcada tanto pela boa avaliação do governo do presidente Lula (PT) quanto pelas denúncias de corrupção dentro de seu partido e dos partidos da base aliada de seu governo. Por conta disso, esse constitui um bom caso para se testar essas hipóteses derivadas do modelo de Inteligência Afetiva, pois, assim como, de um lado, seu governo gerou entusiasmo, por outro, provocou ansiedade nos eleitores.

Com esse estudo, nosso principal objetivo é demonstrar que a clássica antítese entre razão e emoção pode representar uma falácia e que a assimilação de teorias que incorporem as emoções para explicar o comportamento eleitoral pode ser bastante elucidativa para se entender a racionalidade do voto. 


\section{O modelo de Inteligência Afetiva}

O modelo de Inteligência Afetiva tem como pressuposto básico a ideia de que as emoções surgem anterior e independentemente da atividade cognitiva. Segundo Marcus et al, (2000), isso ocorre porque o processamento das informações é feito primeiramente por regiões do cérebro ligadas, dentre outras coisas, à ativação de estados emocionais ${ }^{2}$.

Esse modelo advoga que as emoções possuem duas dimensões distintas: uma dimensão positiva, denominada entusiasmo, e outra negativa, chamada ansiedade. Tais emoções não possuem apenas uma função avaliativa, no sentido de que se o sentimento é negativo, as considerações cognitivas em relação ao objeto que engendra tal sentimento também serão, ou se positivo, que tenderemos a avaliá-lo melhor. A função das emoções dentro desse modelo é um pouco mais complexa: por um lado, regulam comportamentos rotineiros e, por outro, a atenção consciente. Nesse sentido, essa teoria estabelece a existência de dois sistemas afetivos independentes e pré-conscientes que afetam tanto o pensamento quanto o comportamento humano: o sistema de predisposição (disposition system) e o sistema de vigilância (surveillance system).

O sistema de predisposição corresponde à dimensão afetiva do entusiasmo. Trata-se de um sistema afetivo que possui duas principais funções: engajar os comportamentos em hábitos apreendidos pela memória procedimental e adquirir novas rotinas comportamentais. Nesse sentido, quanto maior o sentimento de entusiasmo, mais o comportamento corrente é reforçado. Ao contrário, quando falhamos ou nossas ações não atingem o fim esperado, esse entusiasmo diminui e tendemos a nos manter complacentes e desinteressados em continuar com dadas ações.

Ele é também um sistema de aprendizado e, nesse sentido, na medida em que adquirimos conhecimento rotineiro conseguimos, por exemplo, dirigir sem pensar quando devemos trocar a marcha, ou como dançar sem relembrar os passos a cada momento, ou ainda como devemos nos comportar em cada contexto social.

\footnotetext{
2 Segundo os autores, pesquisas na área de neurociência demonstram haver duas trilhas pelas quais as informações sensoriais - ou seja, as informações obtidas pelos sentidos humanos - e somáticas são processadas pelo cérebro humano. Primeiramente o fluxo de informações segue para a região límbica do cérebro, onde os estados emocionais são ativados, e posteriormente para as demais regiões do córtex que processam essas informações de acordo com suas respectivas funções fisiológicas (motora, visão, audição, etc.), inclusive regiões do cérebro ligadas à consciência. Nesse sentido, a principal diferença entre essas duas trilhas é de que a trilha para a região límbica alcança uma avaliação da informação sensorial e somática em menos da metade do tempo que tal informação leva para se tornar consciente. Dessa forma, "o produto da trilha que leva à região límbica, a trilha que dentre outras capacidades produz estados emocionais, está bem posicionada para influenciar a atenção consciente, assim como o comportamento" (MARCUS, MACKUEN \& NEUMAN, 2000, p.38).
} 
Para situações corriqueiras, o sistema de predisposição é quem oferece o viés para o comportamento humano. Entretanto, situações inesperadas são colocadas a todo o momento para as pessoas e, consequentemente, o repertorio de tal sistema se torna insuficiente para lidar com elas. Nesse momento o sistema de vigilância é ativado.

Já o sistema de vigilância corresponde ao sentimento de ansiedade. Ele busca vigiar o ambiente contra ameaças repentinas, gerando esse tipo de sentimento negativo na medida em que nos defrontamos com elas, e um sentimento de calma, quando não existe ameaça alguma. Este segundo sistema emocional possui a propriedade de interromper comportamentos rotineiros e orientar a atenção para o objeto que engendra uma resposta afetiva desse sistema.

Quando comportamentos rotineiros falham (por exemplo, ao se falar errado ou tropeçar), as emoções se tornam manifestas, bem como as considerações racionais em relação ao objeto que a desperta. Nesse sentido, a principal característica do sistema de vigilância reside na sua capacidade de levar as pessoas a pensarem. Na medida em que circunstâncias novas emergem, as pessoas buscam entender o que acontece e passam a questionar se o comportamento corrente é adequado. Nesse momento, o sistema de predisposição "evoca grande atenção, grande cuidado, e aumenta a motivação pelo aprendizado naquelas situações que demandam grande consideração" (MARCUS et al, 2000, p. 57).

Basicamente, como as pessoas comumente não pensam em política, o argumento dos autores é de que o sistema de predisposição guia o comportamento político humano, sendo tal comportamento governado pelos hábitos dos indivíduos. Isso ocorre por que os comportamentos rotineiros são desempenhados em ambientes já conhecidos, fato que desonera a atenção consciente, levando os eleitores a aderirem a comportamentos eleitorais intuitivos.

Entretanto, tais hábitos podem ser interrompidos na medida em que o sentimento de ansiedade aumenta. Eleitores com alto grau de ansiedade tendem a deixar suas predisposições de lado e passam a comparar os candidatos para decidir a direção de seu voto.

A revisão dos hábitos, estimulada pelo sentimento de ansiedade, aumenta o interesse dos eleitores pelos fatos correntes e, dessa forma, estimula o aprendizado político. Eleitores ansiosos tendem a ser mais atentos às notícias políticas, buscando informações que permitam a tomada de decisão. Nesse sentido: "pessoas ansiosas demonstram maior conformidade [...] com os requisitos formais do modelo da teoria da escolha racional: consideração consciente explícita das utilidades comparadas de cada escolha disponível, investida da melhor informação corrente, e diminuição da motivação em utilizar heurística e atalhos habituais" (MARCUS et al, 2000, p.58). 
Em suma, o modelo de Inteligência Afetiva estabelece que quando os sentimentos são de entusiasmo, os eleitores tendem a se guiar por suas predisposições. Entretanto, quando a ansiedade aumenta, considerações sobre os elementos que engendram tal sentimento são levadas à consciência e os eleitores passam a indagar se vale à pena ou não continuar a se pautar por seus hábitos. Dessa forma,

“A principal hipótese do modelo de inteligência afetiva é de que o sistema de vigilância dita para as pessoas quando elas podem seguramente contar com as habilidades irrefletidas do sistema de predisposição para iniciar e manejar hábitos regulares de nossas vidas. Ela também dita para as pessoas quando elas devem deixar seus hábitos de lado para engajar em uma consideração mais explicita e atenta da melhor coisa a ser feita" (MARCUS et al, 2001,p.58).

\section{A mensuração e a estrutura das emoções}

Do ponto de vista da precisão metodológica, a mensuração de emoções em pesquisas de survey possui uma grande vantagem em relação à mensuração de aspectos cognitivos: as emoções são mais permanentes na subjetividade humana do que impressões cognitivas de um dado evento. As pessoas podem não se lembrar muito bem o que aconteceu ou foi dito numa situação específica, mas as emoções despertadas por um dado discurso ou evento permanecem na subjetividade (ZANJOC, 1980; 1984). Por conta disso, medidas emocionais oferecem uma forma mais precisa de mensurar aspectos subjetivos do que muitas outras que buscam, por exemplo, reconstruir memórias dos entrevistados em relação a situações específicas (TORANGEAU et al, 2000).

Medidas emocionais em survey são utilizadas nos Estados Unidos desde meados da década de 1980, tanto através de perguntas abertas ("como você se sente em relação a X") quanto através de perguntas fechadas, principalmente termômetros afetivos (por exemplo, escalas de 0.100) e baterias de termos afetivos (em que é requisitado aos entrevistados responderem se possuem dados sentimentos em relação a determinado candidato ou o quanto e com que frequência possuem esses sentimentos).

Neste artigo, utilizamos medidas emocionais derivadas de perguntas fechadas, com baterias de termos afetivos, extraídas de um survey nacional 
realizado em outubro de $2006^{3}$. Nele a seguinte questão foi apresentada aos entrevistados:

"Agora eu gostaria de saber sobre seus sentimentos em relação aos candidatos a presidente. Não existe resposta certa ou errada, eu quero saber sua primeira impressão. Em relação a (NOME DO CANDIDATO), pela pessoa que ele é, ou por algo ele já tenha feito, ele te faz sentir (LER CADA SENTIMENTO) - SIM OU NÃO? (COMPLEMENTE: SIM muito(a) ou pouco(a)? / NÃO : pouco(a) ou nenhum(a)?): Empolgação; Aflição; Ódio; Esperança; Medo; Desprezo; Orgulho; Amargura; Angústia; Ressentimento; Decepção; Felicidade."

Segundo Marcus (2003), as abordagens teóricas sobre as emoções dentro da psicologia se concentram em torno da problemática da redução de termos. Esse autor argumenta que existe dentro da cultura anglo-saxã uma variedade de vocábulos que se referem aos sentimentos: raiva, amor, amargura, entusiasmo, inquietude, etc. Todos eles são conceitos de estados emocionais que, de alguma forma, diferem um do outro. Nesse sentido, a grande questão dos estudos de psicologia que versam sobre esse tema é buscar entender como a estrutura dos sentimentos se dispõe, ou seja, se os termos afetivos são todos distintos ou se há alguma forma de equivalência entre eles. Em face dessa questão, esse autor argumenta que as abordagens sobre a estrutura das emoções podem ser divididas em três tipos: a teoria discreta, a de valência e a teoria dimensional.

A teoria que mais busca encontrar equivalência entre conceitos e reduzir o número de termos afetivos é a chamada teoria de valência emocional. Essa teoria argumenta que a estrutura das emoções é disposta em um plano unidimensional e bipolar. Ela afirma, portanto, que a avaliação emocional ocorre através de uma estrutura binária, sendo que em um extremo dessa dimensão se encontra uma valência positiva de sentimentos e de outro uma valência negativa, tal como "bom. mal", "gosto - detesto" ou "amor-ódio". Dessa forma, a teoria de valência coloca a existência de uma relação de exclusão entre sentimentos negativos e positivos: quanto maior for um sentimento positivo em relação a um objeto, menor será o sentimento negativo em relação a ele.

A teoria discreta por sua vez é a que mais busca demonstrar como os sentimentos possuem vários significados. Ela rejeita claramente a teoria de valência e argumenta que os sentimentos são derivados de situações cognitivas específicas. Para essa teoria "é a interpretação dos eventos, mais do que os eventos por si só,

3 Trata-se de um survey nacional com amostra 2400 entrevistas, divididas através de cotas socioeconômicas e demográficas representativas do eleitorado brasileiro. Foram feitos dois splits nesse survey, sendo que as emoções dos eleitores foram mensuradas apenas em um split com cerca de 1200 entrevistas. Agradeço a Orjan Olsen, da Analítica Consultoria, pelo espaço em suas pesquisas para incluir as questões emocionais e pelo apoio no desenvolvimento deste artigo. 
que determinam qual emoção será sentida" (ROSEMAN, 1984, p.14 apud MARCUS, 2003). Assim, tal teoria argumenta que diferentes combinações entre estados emocionais e fatores contextuais produzem distintas interpretações que ativam emoções consoantes a elas.

Marcus (2003) argumenta que as diferentes teorias discretas existentes reduzem os sentimentos para um número entre 8 a 16 sentimentos básicos, todos eles relacionados com considerações contextuais. Tais considerações iniciam com a avaliação de que tipo de sentimento é despertado: negativo ou positivo. Porém esse sentimento é apenas definido posteriormente por uma avaliação cognitiva do contexto em que esse sentimento é ativado. Nesse sentido, por exemplo, uma situação percebida como punitiva será prontamente experimentada com um sentimento negativo, mas esse sentimento será experimentado, por exemplo, com resignação se a responsabilidade dessa situação vivida for atribuída a si mesmo, ou de raiva ou medo se essa responsabilidade for atribuída à outra pessoa. Colocando em termos mais concretos, se um indivíduo perde sua carteira, ele pode sentir medo de que seus pertences sejam mal utilizados por outrem, ou angustiado por ter sido desleixado; mas se sua carteira é roubada seu sentimento pode ser de ódio e raiva pelo assaltante que a roubou. Nessa teoria, portanto os sentimentos dependem da forma como as situações são entendidas cognitivamente pelas pessoas.

Por fim, a teoria dimensional argumenta que a estrutura das emoções é composta por duas dimensões, uma negativa e outra positiva. Diferentemente da teoria de valência e da teoria discreta, essa teoria argumenta que a relação entre sentimentos negativos e positivos não é mutuamente excludente (trata-se de duas dimensões unipolares), mas que é possível identificar simultaneamente sentimentos positivos e negativos em relação a um mesmo objeto. Nesse sentido, saber qual é o impacto emocional positivo de um dado objeto não é o mesmo que saber o impacto inverso das emoções negativas derivadas desse mesmo objeto.

Seguindo essa lógica, a teoria dimensional também argumenta que a estrutura das emoções se dispõe em um plano ortogonal, ou seja, a interação entre a dimensão positiva e negativa produz um ângulo reto $\left(90^{\circ}\right)$. Isso significa dizer que o índice de correlação entre essas dimensões tende a zero e que existe uma independência entre elas, fato que explica por que um sentimento negativo não representa o inverso de um sentimento positivo dentro dessa teoria.

O modelo de Inteligência Afetiva se baseia nessa última teoria da estrutura das emoções e busca demonstrar de que forma as dimensões positiva e negativa interagem na produção de raciocínios em relação ao universo político. Nesse sentido, para verificar a adequação dos dados pesquisados ao teste do modelo teórico de Inteligência Afetiva são necessários dois critérios: demonstrar que essas 
medidas apreendem duas dimensões emocionais, e que a relação entre essas dimensões apontam para uma solução geométrica ortogonal.

Em relação ao primeiro critério, e seguindo os trabalhos de Marcus e seus vários colaboradores, a análise da estrutura das emoções pode ser empreendida através de uma análise fatorial. Para a análise da estrutura das emoções a lógica aplicada é a seguinte: se a teoria discreta estiver correta, o número de fatores da analise fatorial será tão grande quanto possível e, em último caso, cada um dos termos definirá um componente fatorial. Caso a teoria de valência emocional seja adequada, o número de fatores será apenas um na análise fatorial, definindo uma unidimensionalidade bipolar das emoções. Por fim, se a teoria dimensional for de fato a que melhor define a estrutura das emoções, devemos encontrar dois componentes fatoriais.

Para replicar os resultados obtidos pelos trabalhos de Marcus e colaboradores, foi adotado o método de análise de componentes principais ${ }^{4}$ e a rotação varimax ${ }^{5}$. A Tabela 1 mostra os resultados ${ }^{6}$. Valores acima de 0,5 (marcados em negrito) denotam que a variável pertence a um determinado componente fatorial, enquanto valores abaixo desse valor demonstram seu não pertencimento.

Dessa forma, observa-se a existência de dois componentes fatoriais derivados desse formato de mensuração dos sentimentos dos eleitores em relação aos candidatos. Além disso, pode-se perceber que todos os sentimentos positivos possuem pertencimento ao mesmo componente fatorial, enquanto os sentimentos negativos formam outra dimensão distinta.

\footnotetext{
${ }^{4}$ A análise das componentes principais busca explicar a estrutura da variância e da covariância através de poucas combinações lineares das variáveis originais. Segundo Pereira (2004), nessa forma de análise "primeiro identifica-se a dimensão que melhor distingue os objetos, em seguida, a função ortogonal a ela; não estando os objetos perfeitamente discriminados, um novo componente discriminador será buscado, a função ortogonal derivada e assim por diante" (PEREIRA, 2004, p.118).

${ }^{5}$ Segundo Hair et al (2005), a rotação varimax é um dos métodos de rotação ortogonal (onde os eixos dos fatores são mantidos a $90^{\circ}$ e são mantidos não correlacionados) mais populares. Ela se caracteriza pelo fato de oferecer uma solução mais simples das colunas de matriz fatorial e apresentar uma separação mais clara dos fatores. Ela assim o faz através da geração de cargas fatoriais mais próximas de 1 , indicando uma clara associação positiva entre as variáveis, ou mais próximas de 0 , sinalizando a ausência de associação.

${ }^{6}$ Nesta e nas demais tabelas de análise fatorial foi utilizado o método pairwise e, dessa forma, excluídos os missing cases e a categoria não sabe/não respondeu (NS/NR).
} 
PIMENTEL JUNIOR, T. J. Razão e emoção no voto: o voto na eleição presidencial de 2006.

Tabela 1

Análise Fatorial Varimax dos termos emocionais utilizados para descrever os sentimentos por Geraldo Alckmin e Lula

\begin{tabular}{|c|c|c|c|c|c|}
\hline \multirow{2}{*}{ Alckmin } & \multicolumn{2}{|c|}{ Componentes } & \multirow{2}{*}{ Lula } & \multicolumn{2}{|c|}{ Componentes } \\
\hline & 1 & 2 & & 1 & 2 \\
\hline Amargura & 0,866 & 0,027 & Angústia & 0,852 & $.0,095$ \\
\hline Angústia & 0,861 & 0,003 & Amargura & 0,837 & $.0,043$ \\
\hline Desprezo & 0,855 & $-0,017$ & Desprezo & 0,795 & $-0,060$ \\
\hline Ressentimento & 0,833 & 0,049 & Ressentimento & 0,780 & $-0,117$ \\
\hline Decepção & 0,783 & $.0,113$ & Ódio & 0,716 & $.0,090$ \\
\hline Ódio & 0,753 & 0,028 & Medo & 0,699 & $.0,170$ \\
\hline Aflição & 0,709 & $.0,014$ & Aflição & 0,698 & $.0,080$ \\
\hline Medo & 0,708 & $.0,139$ & Decepção & 0,590 & $-0,457$ \\
\hline Empolgação & $.0,103$ & 0,841 & Felicidade & $.0,077$ & 0,855 \\
\hline Felicidade & 0,010 & 0,831 & Esperança & $.0,257$ & 0,820 \\
\hline Esperança & $-0,173$ & 0,821 & Orgulho & $.0,003$ & 0,809 \\
\hline Orgulho & 0,169 & 0,791 & Empolgação & $.0,094$ & 0,803 \\
\hline
\end{tabular}

Fonte: Analítica Consultoria, outubro de 2006.

Entretanto, não basta apenas que existam dois componentes fatoriais para que a teoria dimensional seja corroborada. É preciso também demonstrar a existência de uma relação ortogonal entre elas. Uma forma de analisarmos esse segundo critério é através da visualização gráfica scatterplot da análise fatorial varimax. Nesse caso, a lógica é a seguinte: para se constatar uma relação ortogonal entre os componentes fatoriais é necessário que os termos afetivos de um dos componentes fatoriais se concentrem próximos ao eixo das abscissas e os termos afetivos do outro componente se encontrem junto ao eixo das ordenadas, formando um ângulo de $90^{\circ}$.

Nos Gráficos 1.1 e 1.2 pode-se observar essa relação ortogonal entre os sentimentos positivos, que se encontram junto ao eixo da abscissa, e os sentimentos negativos, que se localizam junto ao eixo da ordenada. Nelas observase que essa mensuração oferece o tipo de disposição geométrica requerida para que se constate a independência dessas duas dimensões, pressuposto obrigatório para que pudéssemos testar as hipóteses derivadas do modelo de Inteligência Afetiva. 
Gráfico 1.1- Análise Fatorial Varimax dos termos emocionais dicotômicos utilizados para descrever os sentimentos por Alckmin (outubro).

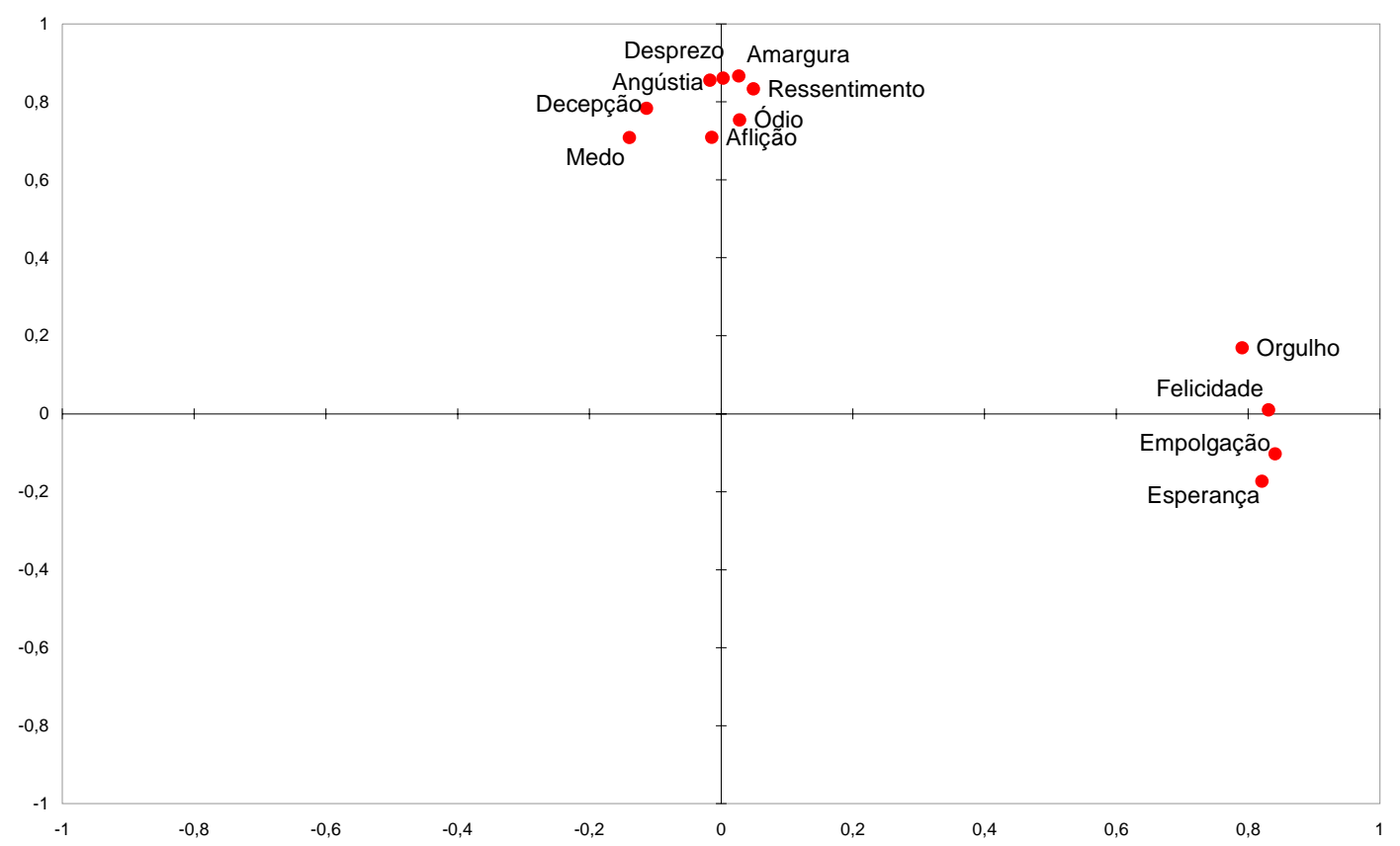

Gráfico 1.2- Análise Fatorial Varimax dos termos emocionais dicotômicos utilizados para descrever os sentimentos por Lula (Outubro).

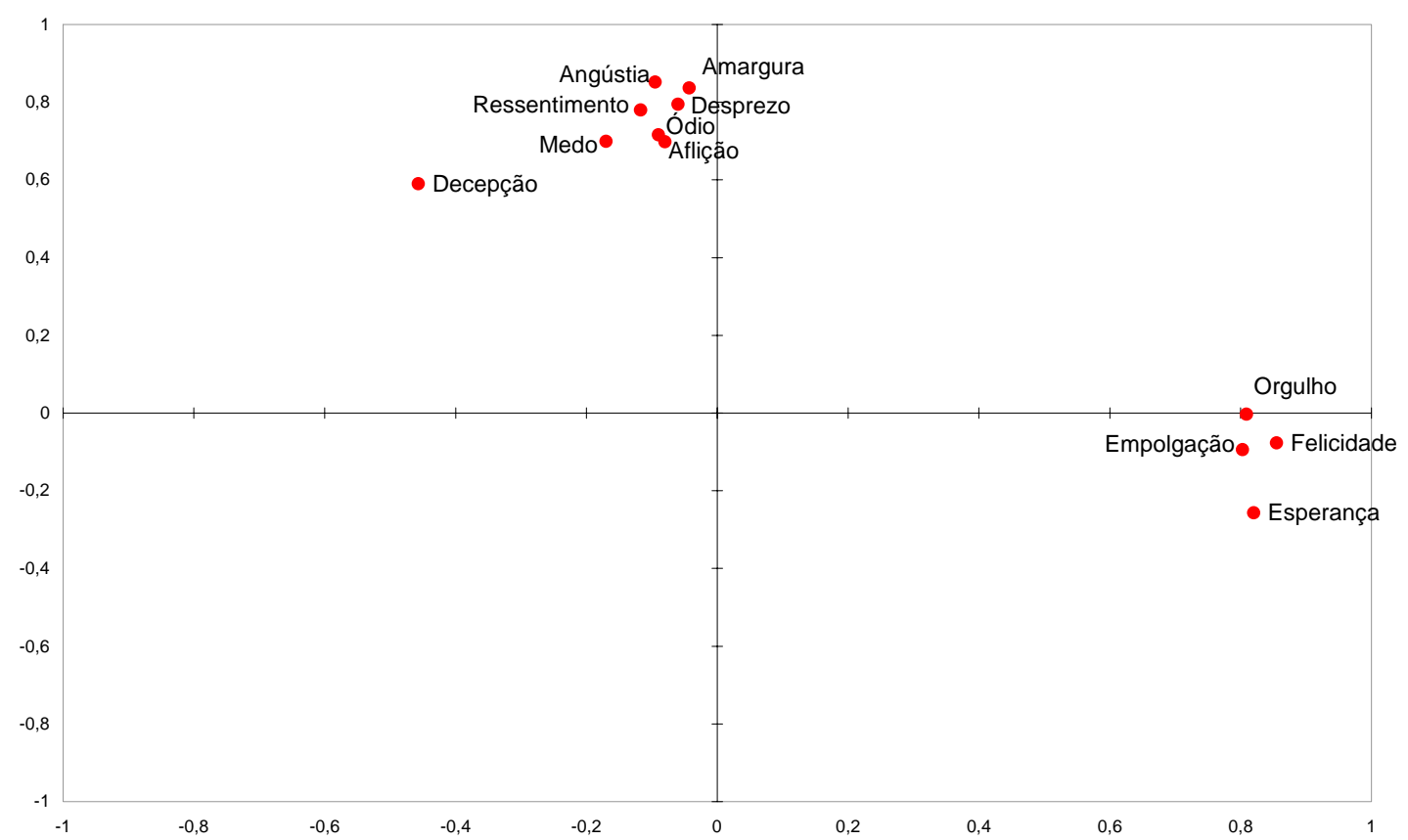


Esses dados possibilitaram construir duas escalas ${ }^{7}$ para mensurar as emoções pelos candidatos, uma escala de entusiasmo e outra de ansiedade para cada um dos candidatos, formando o seguinte quadro de distribuição de intensidade de entusiasmo e ansiedade para Lula e Alckmin:

Tabela 2

Intensidade de sentimentos por Lula e Alckmin

\begin{tabular}{|l|c|c|c|c|}
\hline & $\begin{array}{c}\text { Entusiasmo } \\
\text { Lula }\end{array}$ & $\begin{array}{c}\text { Ansiedade } \\
\text { Lula }\end{array}$ & $\begin{array}{c}\text { Entusiasmo } \\
\text { Alckmin }\end{array}$ & $\begin{array}{c}\text { Ansiedade } \\
\text { Alckmin }\end{array}$ \\
\hline Nenhum & 24 & 33 & 27 & 51 \\
\hline Não pouco & 20 & 32 & 27 & 28 \\
\hline Sim- pouco & 23 & 20 & 24 & 12 \\
\hline Sim- Muito & 32 & 14 & 19 & 5 \\
\hline NS/NR & 1 & 1 & 3 & 3 \\
\hline
\end{tabular}

Pode-se observar que, do ponto de vista emocional, Lula levava clara vantagem em relação a Alckmin. Os eleitores possuíam um grau de entusiasmo maior em relação à Lula do que em relação a Alckmin, com 55\% dos eleitores declarando esse entusiasmo pelo presidente e $34 \%$ para o candidato da oposição. Se levarmos em consideração a interpretação de Westen (2007) de que a batalha pelo voto é basicamente uma batalha para se ganhar as emoções dos eleitores, podemos entender melhor por que naquele contexto Lula levou a melhor sobre Alckmin.

\section{Hipóteses e análise dos dados}

No modelo de Inteligência Afetiva existem três fatores que podem engendrar sentimentos nos eleitores: "Os candidatos, as questões políticas [issues] ou os tempos em que eles [os eleitores] vivem" (MARCUS et al, 2000, p.63-4). A avaliação retrospectiva de governo se encaixa nesse último tipo.

Sem dúvida, a mais óbvia realidade contextual que determina "os tempos" (ou as condições) em que os eleitores vivem é a situação da economia nacional. $O$ argumento dos autores do modelo de Inteligência Afetiva é que o estado da economia é uma das variáveis que mais gera ansiedade e entusiasmo no eleitorado. Dessa forma, situações em que a economia vai mal, onde existe grande

7 As escalas de ansiedade e entusiasmo foram feitas através do cálculo da soma da média dos sentimentos ligados a cada uma dessas dimensões. Dessa forma, o entusiasmo corresponde à soma da média das variáveis Empolgação, Orgulho, Esperança e Felicidade, enquanto a ansiedade foi resultado da soma da média das variáveis Aflição, Decepção, Angústia, Medo, formando-se assim duas escalas das emoções para cada um dos candidatos. 
desemprego, baixos salários e pouca atividade comercial, levam os eleitores a se tornarem mais ansiosos. Ao contrário, se existe prosperidade econômica, os empregos e salários aumentam, os eleitores tendem a ficar mais entusiasmados com os governantes e a direcionar-Ihes o voto.

O que esse modelo argumenta portanto que é a avaliação retrospectiva não é puramente racional. Eleitores não precisam estar conscientes das realizações do governo para compreender que a situação do país é melhor ou pior e nem verbalizar as razões disso. Esse comportamento pode se dar meramente por uma intuição afetiva, de modo que, se a situação vai bem, sentimentos de entusiasmos são engendrados, enquanto que se a situação vai mal, o sentimento de ansiedade aumenta.

Tendo em conta a teoria do voto retrospectivo, nossos dados revelam que a maioria dos eleitores aprovou o governo Lula. A avaliação desse governo foi considerada boa ou muito boa por $47 \%$, e somente $13 \%$ consideraram o governo ruim ou muito ruim. Tal como estabelece o modelo de Inteligência Afetiva, a avaliação retrospectiva de governo é uma das variáveis independentes que explica os sentimentos dos eleitores em relação aos candidatos.

A Tabela 3 mostra os valores de correlação gama ${ }^{8}$ entre a avaliação do governo Lula e os sentimentos dos eleitores em relação a Lula e Alckmin. Nela observa-se que o sentimento mais correlacionados com a avaliação de governo é o entusiasmo em relação a Lula, com índice de 0,705. Observa-se também uma correlação negativa entre o sentimento de ansiedade em relação a Lula e a avaliação de seu governo de -0,514. Essa tabela denota ainda uma relação de exclusão mútua no eleitorado: eleitores que avaliam bem o governo Lula tendem a ter sentimentos de ansiedade em relação a Alckmin (uma correlação positiva de 0,360 ) enquanto que eleitores que avaliam bem esse governo tendem a possuir menos sentimento de entusiasmo em relação ao candidato do PSDB (uma correlação negativa de $\cdot 0,493$ ).

\footnotetext{
8 Segundo Babbie (2005), o índice de correlação gama é o mais adequado para se tratar variáveis ordinais. Como nossas variáveis que mensuram as emoções são ordinais utilizamos esse índice com o intuito de analisar a força de associação entre essas variáveis e as variáveis dependentes.
} 
Tabela 3

Avaliação do Governo Lula e as Emoções

\begin{tabular}{|l|l|}
\hline & Avaliação Governo Lula \\
\hline Entusiasmo Lula & $0,705^{*}$ \\
\hline Ansiedade Lula & $-0,514^{*}$ \\
\hline Entusiasmo Alckmin & $-0,493^{*}$ \\
\hline Ansiedade Alckmin & $0,360^{*}$ \\
\hline
\end{tabular}

*Correlações significativas a 0,001

Fonte: Analítica Consultoria, outubro de 2006

Não obstante o bom desempenho do governo Lula, as crises de corrupção foram outra marca deixada por esse governo. As três principais foram o caso da quebra do sigilo bancário do caseiro Francenildo Costa, o "Mensalão" e o caso do dossiê.

Em março de 2006, o caseiro Francenildo Costa foi ouvido pela CPI dos Bingos e declarou ter visto o Ministro Antonio Palloci em uma mansão utilizada em Brasília por lobistas para fechar negócios suspeitos e promover festas com prostitutas. O ministro havia negado várias vezes na CPI ter frequentado essa casa, conhecida como "República de Ribeirão Preto"9. Poucos dias depois dessa declaração de Francenildo, os dados de movimentação de sua conta bancária foram divulgados pela imprensa, denunciando que o caseiro havia recebido cerca de 35 mil reais em depósitos, valor incompatível com sua renda mensal de 700 reais. Essa denúncia tinha como intuito desqualificar as declarações do caseiro, aventando-se a hipótese de que ele teria recebido esse dinheiro para mentir na CPI e prejudicar Palloci ${ }^{10}$.

Soube-se, no entanto, que tais depósitos teriam sido feitos por Eurípedes Soares da Silva, empresário do setor de transporte do Piauí e pai biológico de Francenildo. Embora negasse a paternidade, decorrente de uma relação extraconjugal, Eurípedes confirmou ter feito o depósito. Esclarecida essa situação, o foco passou a ser a quebra do sigilo bancário de Francenildo, ato ilegal já que havia sido feito sem o aval da justiça. O nome de Palloci foi logo envolvido nesse processo, o que levou a queda de uma das figuras mais fortes do governo.

Em junho de 2005, outro escândalo irrompeu dentro do governo Lula. Mais uma vez a prova foi uma fita de vídeo que mostrava o ex-funcionário dos Correios, Maurício Marinho, negociando propina com empresários interessados em uma

\footnotetext{
9 Inquérito sobre a violação do sigilo do caseiro vai para STF. Folha de São Paulo, 08 fev. 2007.

10 Marinho afirma que caseiro foi "treinado" e "inventado", Folha de São Paulo, 20 mar. 2006.
} 
licitação. Nesse vídeo, Marinho dizia ter respaldo do Deputado Roberto Jefferson (PTB) para promover essa negociação ilícita.

Acuado, Roberto Jefferson ${ }^{11}$ passou a denunciar deputados da base governista de receberem um "mensalão" de 30 mil reais do tesoureiro do PT, Delúbio Soares. Segundo Jefferson afirmou à época, o dinheiro do mensalão vinha de empresas estatais e privadas e era entregue aos parlamentares por operadores como o publicitário Marcos Valério e o líder do PP na câmara, José Janene. A partir disso foi deflagrada a CPI dos Correios para investigar o envolvimento de empresas estatais para alimentar os recursos do "mensalão"12.

As denúncias de Jefferson atingiram diretamente a cúpula do PT e nomes como o chefe da Casa Civil, José Dirceu, o então presidente do PT, José Genoíno, o secretário geral do PT, Sílvio Pereira, além do já mencionado Delúbio Soares. Os desgastes provocados por essas denúncias levaram à queda de José Dirceu, até então principal figura do governo Lula, e de José Genoíno, umas das principais lideranças históricas do PT.

As revelações de Jefferson envolviam indiretamente também o presidente Lula, pois, segundo o ex-deputado, desde o começo de 2005 o presidente tinha ciência dos fatos ocorridos, mas até então não tinha tomado nenhuma providência. Mas, neste caso, o impacto foi quase nulo. Para a população, parece ter sido suficiente a declaração do presidente de que "não sabia de nada" do que estava acontecendo e que se soubesse teria tomado as atitudes cabíveis.

Já durante a campanha, quase a quinze dias do primeiro turno, outro escândalo surgiu. Trata-se do caso da tentativa de compra de um dossiê pelos petistas Gedimar Passos e Valdebram Padilha das mãos de Paulo Trevisan e Luis Antonio Vedoin, sócios da empresa Planan, que já haviam sido envolvidos em outro escândalo de corrupção deflagrada pela "operação sanguessuga"13. A polícia federal prendeu os envolvidos em um hotel em São Paulo antes de essa transação ter sido realizada e apreendeu cerca de 1,75 milhões de reais em dinheiro com os petistas. Posteriormente, às vésperas do primeiro turno, as fotos do dinheiro apreendido vazaram na mídia.

\footnotetext{
11 Roberto Jefferson teve seu mandato cassado pelo congresso por quebra do decoro parlamentar por não conseguir provar que o mensalão existia, ironicamente a CPI do mensalão concluiu posteriormente que o mensalão de fato existiu. Segundo o relatório dessa CPI: "houve recebimento de vantagens indevidas por parlamentares e dirigentes partidários com peridiocidade variável, mas constante em 2002 e 2003. Chama-se isso mensalão quem quiser; chame-se isso quinzenão quem quiser; chama-se se isso semanão quem quiser". Por 23 assinaturas, CPI do mensalão chega ao fim". Folha de São Paulo, 18 nov. 2005.

12 Caso do Mensalão teve início com a denúncia de Roberto Jefferson, Folha de São Paulo, 02 jul. 2005.

13 A "operação sanguessuga" da polícia federal desmontou a quadrilha que fraudava a venda de ambulâncias para vários estados do Brasil, através de emendas de parlamentares que superfaturavam seus preços. Foram indicados como chefes dessa quadrilha membros da família Trevisan Vedoin, cabendo a Planan a montagem e a entrega das ambulâncias.
} 
Supostamente, o conteúdo desse dossiê traria provas de que alguns políticos, dentre eles o candidato ao governo do estado de São Paulo e ex-ministro da saúde José Serra, estariam envolvidos na liberação de verbas orçamentárias para a compra de ambulâncias superfaturadas. O conteúdo desse dossiê, portanto, poderia comprometer a candidatura de Serra e, teoricamente, poderia favorecer o candidato petista Aloísio Mercadante. Porém, a ação da polícia federal gerou um resultado adverso às intenções dos petistas envolvidos nesse caso.

Ao final da campanha presidencial no primeiro turno, a ausência de Lula do debate entre candidatos na Rede Globo de Televisão no primeiro turno, logo após esses escândalos somente serviu para piorar a situação do então Presidente da República. Esta seria uma ótima oportunidade para que o presidente se defendesse das acusações de forma que seus eleitores pudessem ouvir do próprio candidato sua versão dos fatos, mas sua atitude acabou gerando a oportunidade para que os seus opositores o criticassem. Nessa oportunidade, Geraldo Alckmin atacou o presidente da seguinte forma: "O Lula, com sua ausência aqui nesse debate, mandou um recado aos brasileiros: 'Eu não estou interessado em sua opinião, eu não preciso prestar contas para ninguém'. Domingo, mande um recado para ele e mude de presidente ${ }^{14 "}$.

O modelo de Inteligência Afetiva advoga que o entusiasmo atua de maneira a predispor os indivíduos a votarem em determinado candidato. Assim, eleitores entusiasmados com o governante estão muito mais propensos a decidirem seu voto em etapas iniciais das campanhas, ou até mesmo antes delas, do que eleitores que possuam pouco entusiasmo. Da mesma forma, eleitores ansiosos em relação ao governante, por conta da incerteza gerada por fatores de curto prazo, tendem a decidir mais tardiamente. Tendo isso em conta, as hipóteses aventadas por esse artigo são de que os eleitores mais entusiasmados por Lula tenderam a decidir mais cedo em quem votar, enquanto que eleitores mais ansiosos em relação a ele tenderam a decidir posteriormente aos fatores de curto prazo relacionados ao caso do dossiê.

De fato, os dados que possuímos corroboram essas duas hipóteses, tal como pode ser observado na Tabela 4 . O primeiro ponto a observar é o percentual de pessoas que já haviam decidido há muito tempo, $82 \%$, indicando que boa parte dos eleitores não foi afetada por fatores de curtíssimo prazo postos na campanha ${ }^{15}$.

\footnotetext{
${ }^{14}$ Ausência de Lula e corrupção dominam debate entre presidenciáveis, Folha Online, 29/09/2006.

$15 \mathrm{Na}$ Tabela 3, a pergunta utilizada para mensurar o tempo de decisão do voto foi a seguinte: "Em que momento o(a) Sr(a) decidiu a escolha do seu voto para presidente no primeiro turno?" Sendo oferecida as seguintes categorias de estímulo: Depois do escândalo do dossiê, depois do debate da globo, depois da divulgação das fotos, no dia da eleição ou já havida decidido há muito tempo. A resposta era única. Como se trata de uma variável nominal, com a finalidade de analisar a correlação gamma entre sentimentos e o tempo da decisão do voto, cada categoria foi transformada em uma variável dummy, totalizando cinco variáveis distintas, com o valor 1 sendo assumido pela categoria analisada, o valor 0 para as demais categorias e NS/NR como missing cases.
} 
Nessa mesma tabela, a variável com maior nível de correlação com o tempo de decisão do voto é o sentimento de ansiedade em relação à Lula. Tal como já descrito anteriormente, o modelo de Inteligência Afetiva prevê que os sentimentos em relação ao governante influenciam muito mais no processo de decisão dos eleitores do que os sentimentos em relação ao desafiante. De fato, todas as correlações com a ansiedade em relação à Alckmin não demonstram ter significância estatística, indicando a desimportância desse sentimento para o tempo de decisão do voto quando se trata de um desafiante pouco conhecido.

Por esses índices, observa-se também que a divulgação das fotos e a decisão no dia da eleição não possuem correlação com os sentimentos dos eleitores. Por outro lado, existe a tendência de que quanto maior o entusiasmo por Lula, mais cedo havia sido feita a decisão do voto e que, quanto maior a ansiedade, mais tarde os eleitores decidiram em quem votar.

Esses dados mostram que os eleitores mais entusiasmados por Lula tenderam a seguir sua predisposição em votar nele, enquanto eleitores mais ansiosos em relação a ele tenderam a decidir mais tarde, principalmente após o caso do dossiê e da sua ausência no debate televisivo.

Já a correlação entre o tempo de decisão do voto dos eleitores e entusiasmo por Alckmin apresentou um padrão diferente. Como candidato da oposição e pouco conhecido nacionalmente, Alckmin conseguiu gerar entusiasmo no eleitorado no curto prazo e por isso esse sentimento estava positivamente correlacionado com os eventos relacionados ao escândalo do dossiê, e negativamente associada com a categoria "já havia decidido há muito tempo". Eleitores entusiasmados por Alckmin não tenderam a decidir muito tempo antes devido ao fato dele se apresentar nacionalmente aos eleitores somente durante campanha. 
Tabela 4

Tempo da decisão e os sentimentos pelos candidatos

\begin{tabular}{|l|c|c|c|c|c|}
\hline Quando decidiu o voto: & $\mathbf{\%}$ & $\begin{array}{c}\text { Entusiasmo } \\
\text { Lula }\end{array}$ & $\begin{array}{c}\text { Ansiedade } \\
\text { Lula }\end{array}$ & $\begin{array}{c}\text { Entusiasmo } \\
\text { Alckmin }\end{array}$ & $\begin{array}{c}\text { Ansiedade } \\
\text { Alckmin }\end{array}$ \\
\hline $\begin{array}{l}\text { Depois do Escândalo do } \\
\text { Dossiê }\end{array}$ & 6 & $-\mathbf{0 , 3 8 6 ^ { * }}$ & $\mathbf{0 , 4 3 3 ^ { * }}$ & $\mathbf{0 , 2 0 3 ^ { * }}$ & $-0,198^{* *}$ \\
\hline Depois do Debate da Globo & 6 & $-\mathbf{0 , 1 4 9 *}$ & $\mathbf{0 , 4 0 0 ^ { * }}$ & $\mathbf{0 , 2 1 1 ^ { * }}$ & $0,024^{* *}$ \\
\hline $\begin{array}{l}\text { Depois da Divulgação da Foto } \\
\text { do Dinheiro }\end{array}$ & 1 & $-0,350^{* *}$ & $0,317^{* *}$ & $0,347^{* *}$ & $-0,273^{* *}$ \\
\hline No dia da Eleição & 5 & $-0,144^{* *}$ & $0,089^{* *}$ & $-0,091^{* *}$ & $0,109^{* *}$ \\
\hline $\begin{array}{l}\text { Já Havia decidido há muito } \\
\text { tempo }\end{array}$ & 82 & $\mathbf{0 , 2 6 5 ^ { * }}$ & $\mathbf{- 0 , 2 7 1 ^ { * }}$ & $\mathbf{- 0 , 1 0 0 ^ { * }}$ & $0,034^{* *}$ \\
\hline
\end{tabular}

* Significativo a 0,001.

** Não significativo.

Fonte: Analítica Consultoria, outubro de 2006.

Além de ajudar a entender em que momento os eleitores decidiram o voto, o modelo de Inteligência Afetiva nos ajuda também a entender a mudança de voto ${ }^{16}$ durante a campanha. Tal como pode ser visto na Tabela 5, depois do escândalo do dossiê e da ausência de Lula nos debates e da divulgação das fotos, cerca de $20 \%$ dos eleitores, em média, declararam ter deixado de votar no candidato governista. Novamente, o sentimento de ansiedade em relação a Lula é a principal variável que explica essa mudança. Eleitores mais ansiosos por Lula foram os que mais tenderam a deixar de votar nesse candidato após esses eventos; não obstante, quanto maior o entusiasmo por Lula, menor foi essa tendência.

O entusiasmo por Alckmin também é responsável pela mudança no voto por Lula. Do ponto de vista do modelo de Inteligência Afetiva a razão disso é clara: não basta que haja ansiedade em relação ao governante para que os eleitores decidam mudar o voto, é preciso também que haja entusiasmo em relação aos desafiantes.

\footnotetext{
$16 \mathrm{Na}$ Tabela 4, para mensurar a mudança de voto foram utilizadas as seguintes questões: Lula não compareceu a nenhum debate entre os candidatos a presidente. A ausência de Lula nesses debates fez o(a) Sr(a) mudar seu voto, desistindo de votar em Lula?

O envolvimento de petistas e assessores ligados ao presidente Lula no escândalo da compra do dossiê contra os seus adversários fez o(a) Sr(a) mudar seu voto, desistindo de votar em Lula?

A divulgação da foto do dinheiro apreendido com os petistas no escândalo do dossiê contra os seus adversários fez o(a) Sr(a) mudar seu voto, desistindo de votar em Lula? Todas essas variáveis eram nominais e as categorias de estímulos foram Sim ou Não. Essas variáveis dummies foram utilizadas na correlação gamma com Sim assumindo o valor 1, Não assumindo o valor 0 e NS/NR como missing cases.
} 
Tabela 5

Mudança de voto e sentimentos pelos candidatos

\begin{tabular}{|c|c|c|c|c|c|}
\hline $\begin{array}{l}\text { Deixou de votar em } \\
\text { Lula depois do: }\end{array}$ & $\%$ & $\begin{array}{c}\text { Entusiasmo } \\
\text { Lula }\end{array}$ & $\begin{array}{l}\text { Ansiedade } \\
\text { Lula }\end{array}$ & $\begin{array}{l}\text { Entusiasmo } \\
\text { Alckmin }\end{array}$ & $\begin{array}{l}\text { Ansiedade } \\
\text { Alckmin }\end{array}$ \\
\hline Debate & 19 & $-0,300^{*}$ & $0,436^{*}$ & $0,369 *$ & $-0,074$ \\
\hline Dossiê & 21 & $-0,373^{*}$ & $0,497^{*}$ & $0,372^{*}$ & $-0,075$ \\
\hline Fotos & 20 & $-0,400^{*}$ & $0,459 *$ & $0,342^{*}$ & -0,082 \\
\hline
\end{tabular}

A análise dessas duas tabelas corrobora a ideia de que o entusiasmo está correlacionado à disposição em votar em Lula, enquanto a ansiedade está correlacionada com a indecisão (ou postergação da decisão) e a tendência de mudança dessa disposição. Dessa forma, a hipótese que pode ser formulada para testar o efeito das emoções sobre a avaliação retrospectiva de governo é a seguinte: quanto mais positivamente avaliado for o governo e maior ansiedade houver em relação a ele, maior a tendência de que os eleitores tenham decidido o voto após os eventos ligados ao caso do dossiê. Da mesma forma, quanto mais bem avaliado for o governo e maior o entusiasmo em relação a ele, maior a tendência de que os eleitores tenham decidido há mais tempo em quem votar.

A lógica dessa hipótese é de que os eleitores que avaliam melhor dado governante (ou seja, aqueles que possuem maior predisposição em votar nele) quando são tomados pelo sentimento de ansiedade em relação ao candidato governista tendem a ficar mais confusos se devem ou não manter o voto nele e, a partir disso, postergam essa decisão. Isso ocorre, segundo o modelo de Inteligência Afetiva, porque o sentimento de ansiedade engendra o questionamento das predisposições e engaja os eleitores em considerações mais conscientes sobre em quem votar.

A ideia, portanto, é que a correlação entre a predisposição dos eleitores votarem em Lula, dada pela boa avaliação de seu governo, é quebrada pelo sentimento de ansiedade que os eventos de corrupção postos em curto prazo possam ter trazido, e são exatamente aqueles que melhor avaliam esse governo os que possuem maior chance de serem afetados por esse sentimento. Por outro lado, eleitores mais entusiasmados tendem a ignorar esses fatos e a manter sua predisposição em votar em Lula, caso considerem que ele tenha feito um bom governo.

De fato, os dados da Tabela 6 mostram que essas hipóteses estão corretas. Tal como pode se observar pelos índices de correlação gama, foram os eleitores mais ansiosos por Lula os mais propensos a decidir o voto depois do caso do Dossiê e do debate da TV Globo. Entretanto, observa-se também que são, sobretudo, os 
eleitores que mais positivamente avaliam o governo Lula aqueles que mais tenderam a decidir o voto após esses eventos. Nesse sentido, por exemplo, enquanto a correlação entre ansiedade e decisão após o caso dossiê foi de 0,359 para os eleitores que avaliam o governo Lula como regular, esse índice passa para 0,527 para os eleitores que avaliam o governo Lula como "Muito Bom" ou "Bom".

Da mesma forma, eleitores ansiosos por Lula mostram uma tendência maior de não terem decidido seu voto há mais tempo e essa tendência é tanto maior quanto melhor os eleitores avaliam o governo desse candidato (sendo -0,209 para quem avalia como regular e -0,289 para quem avalia o governo Lula como Bom ou Muito Bom). Além disso, pode-se perceber que eleitores mais entusiasmados por Lula e que avaliam positivamente seu governo tenderam a decidir o voto há mais tempo $(0,491)$.

Tabela 6

Avaliação do governo Lula, sentimentos por Lula e tempo de decisão do voto

\begin{tabular}{|c|c|c|c|c|c|c|}
\hline \multirow[b]{2}{*}{$\begin{array}{l}\text { Avaliação } \\
\text { Governo Lula }\end{array}$} & \multirow[b]{2}{*}{$\begin{array}{l}\text { Sentimentos em } \\
\text { relação a Lula }\end{array}$} & \multicolumn{5}{|c|}{ Quando decidiu o voto } \\
\hline & & $\begin{array}{c}\text { Depois do } \\
\text { Dossiê }\end{array}$ & $\begin{array}{c}\text { Depois } \\
\text { do } \\
\text { Debate } \\
\text { na Globo }\end{array}$ & $\begin{array}{c}\text { Depois } \\
\text { das } \\
\text { Fotos }\end{array}$ & $\begin{array}{l}\text { No dia } \\
\text { da } \\
\text { Eleição }\end{array}$ & $\begin{array}{c}\text { Já havia } \\
\text { decidido } \\
\text { há } \\
\text { muito } \\
\text { tempo }\end{array}$ \\
\hline \multirow{2}{*}{$\begin{array}{c}\text { Ruim/ Muito } \\
\text { Ruim }\end{array}$} & Ansiedade Lula & 0,009 & 0,508 & 0,025 & $-0,243$ & $0,196 * *$ \\
\hline & Entusiasmo Lula & 0,153 & 0,768 & 0,759 & $-0,542 *$ & $.0,405$ \\
\hline \multirow{2}{*}{ Regular } & Ansiedade Lula & $0,359 *$ & $0,324^{*}$ & $.0,089$ & 0,032 & $-0,209 *$ \\
\hline & Entusiasmo Lula & $.0,172$ & 0,058 & $-0,024$ & 0,264 & $-0,068$ \\
\hline \multirow{2}{*}{$\begin{array}{l}\text { Boa/Muito } \\
\text { Boa }\end{array}$} & Ansiedade Lula & $0,527^{*}$ & $0,393^{*}$ & 0,612 & 0,132 & $-0,289 * *$ \\
\hline & Entusiasmo Lula & $-0,480^{*}$ & $-0,364 *$ & $-1,000$ & $-0,363^{*}$ & $0,491^{*}$ \\
\hline
\end{tabular}

* correlação significativas até o nível de 0,01.

** correlação significativas até o nível de 0,05.

Fonte: Analítica Consultoria, Outubro de 2006.

Essas correlações podem ser explicadas pelo fato de que são os eleitores com maior disposição em votar no presidente, por conta de seu bom governo, os mais afetados pelo sentimento de que algo não vai bem. Eleitores que avaliam mal o governo são os primeiros a destinar o voto para a oposição, por isso, não faz de fato sentido esse segmento alegar que deixou de votar em Lula após esses eventos de corrupção (possivelmente essa predisposição em votar na oposição foi apenas reforçada com esses eventos). Porém, eleitores que avaliam bem o governo Lula são 
os que mais sentem o impacto desses eventos e tendem a ficar mais ansiosos após eles, fato que explica porque a decisão desse segmento tendeu a ser mais tardia ou motivada por esses fatores de curto prazo.

Entretanto, observa-se também nessa tabela uma correlação significativa entre ansiedade por Lula e a tendência de ter decidido o voto há muito tempo, dentro do segmento dos eleitores que avaliam mal seu governo $(0,196)$. Essa correlação, que parece contradizer nossas hipóteses, na verdade a reforça. Se pensarmos bem, eleitores que avaliam mal o governo Lula e possuem ansiedade em relação a esse candidato na verdade decidiram seu voto há muito tempo justamente por já terem decidido em votar na oposição desde muito cedo, por conta da predisposição negativa gerada por esse governo.

De fato, tal como podemos ver na Tabela 7, eleitores entusiasmados com Alckmin já haviam decidido seu voto há muito mais tempo, principalmente se eles avaliaram o governo Lula como sendo "Ruim" ou "Muito ruim". Ao contrário, podese perceber que, dentro desse segmento de avaliação de governo, quanto maior a ansiedade por Alckmin mais os eleitores tenderam a postergar a decisão. Além disso, nesse segmento de eleitores que avaliam negativamente o governo, observase a existência de uma correlação positiva entre a decisão no dia da eleição e ansiedade por Alckmin.

Tabela 7

Avaliação do governo Lula, sentimentos por Alckmin e tempo de decisão do voto

\begin{tabular}{|c|c|c|c|c|c|c|}
\hline \multirow[b]{2}{*}{$\begin{array}{c}\text { Avaliação } \\
\text { Governo } \\
\text { Lula }\end{array}$} & \multirow[b]{2}{*}{$\begin{array}{l}\text { Sentimentos em } \\
\text { relação a Alckmin }\end{array}$} & \multicolumn{5}{|c|}{ Quando decidiu o voto } \\
\hline & & $\begin{array}{c}\text { Depois } \\
\text { do } \\
\text { Dossiê }\end{array}$ & $\begin{array}{c}\text { Depois } \\
\text { do } \\
\text { Debate } \\
\text { na Globo }\end{array}$ & $\begin{array}{c}\text { Depois } \\
\text { das } \\
\text { Fotos }\end{array}$ & $\begin{array}{l}\text { No dia } \\
\text { da } \\
\text { Eleição }\end{array}$ & $\begin{array}{c}\text { Já havia } \\
\text { decidido há } \\
\text { muito } \\
\text { tempo }\end{array}$ \\
\hline \multirow{2}{*}{$\begin{array}{l}\text { Ruim/ } \\
\text { Muito Ruim }\end{array}$} & Ansiedade Alckmin & 0,202 & 0,132 & 0,547 & $0,646 *$ & $-0,542^{*}$ \\
\hline & Entusiasmo Alckmin & $-0,192$ & $-0,266$ & $-0,142$ & $0, \overline{7} 10 *$ & $0,480 *$ \\
\hline \multirow{2}{*}{ Regular } & Ansiedade Alckmin & $-0,151$ & 0,248 & $-1,000$ & 0,265 & $-0,080$ \\
\hline & Entusiasmo Alckmin & $\cdot 0,039$ & 0,084 & 0,426 & $0, \overline{-}$ & 0,056 \\
\hline \multirow{2}{*}{$\begin{array}{c}\text { Boa/Muito } \\
\text { Boa }\end{array}$} & Ansiedade Alckmin & $-0,146$ & $-0,323$ & $-1,000$ & $-0,217$ & $0,199 * *$ \\
\hline & Entusiasmo Alckmin & 0,343 & 0,312 & $\cdot 1,000$ & 0,321 & $-0,185$ \\
\hline
\end{tabular}

* correlação significativas até o nível de 0,01.

** correlação significativas até o nível de 0,05.

Fonte: Analítica Consultoria, Outubro de 2006. 
Essa correlação pode ser explicada pelo fato de os eleitores sofrerem uma dupla pressão negativa para a tomada de decisão: a má avaliação do governo Lula não criou qualquer predisposição de voto nesse candidato e, ao mesmo tempo, os eleitores também se sentiram ansiosos em relação a Alckmin. O resultado disso é um processo mais minucioso sobre a decisão do voto que os levaram a postergar essa decisão até o último minuto. Ainda dentro desse mesmo segmento da Tabela 6 , percebe-se a existência de uma correlação negativa entre o entusiasmo por Alckmin e essa data de decisão, o que reforça a ideia de que eleitores entusiasmados por esse candidato e que avaliaram mal o governo Lula não deixaram para decidir o voto na última hora. Pelo contrário, pelo fato dessas variáveis estarem correlacionadas no segmento de eleitores que avaliam o governo Lula de maneira negativa, estima-se que a decisão de votar na oposição já tenha sido construída ao longo dos vários anos de atuação do governante.

Essas hipóteses aplicadas para explicar o tempo da decisão também se aplicam para explicar a mudança no voto. Tal como se pode observar na Tabela 8 , eleitores ansiosos por Lula tenderam a deixar de votar nesse candidato depois dos eventos de curto prazo que geraram ansiedade e essa tendência foi tanto maior quanto mais positivamente foi avaliado o governo Lula. Ao contrário, observa-se que eleitores mais entusiasmados por Lula tenderam a manter seu voto (dada a correlação negativa) e essa tendência também foi tanto maior quanto mais positiva a avaliação do governo.

Além disso, da mesma forma que na Tabela 7, percebe-se que no segmento de eleitores que avaliam o governo Lula negativamente não existe qualquer correlação significativa entre os sentimentos por Lula e a mudança de voto. Esse fato denota aquilo já constatado em relação ao tempo de decisão do voto: eleitores que avaliam negativamente o governo Lula tendem desde muito antes a votar na oposição. Por isso mesmo não faz qualquer sentido a ideia de que nesse segmento os eleitores tenham deixado de votar em Lula. O fato é que no modelo de Inteligência Afetiva, a ansiedade serve como um contrapeso à tendência dos eleitores votarem sem nenhuma consideração consciente e indica em que momento eles devem passar a prestar atenção aos acontecimentos políticos, sendo que faz muito mais sentido para os eleitores que avaliam bem o governante. 
Tabela 8

Avaliação do governo Lula, sentimentos por Lula e mudança no voto em Lula

\begin{tabular}{|c|c|c|c|c|}
\hline \multirow{2}{*}{$\begin{array}{c}\text { Avaliação } \\
\text { Governo Lula: }\end{array}$} & \multirow{2}{*}{$\begin{array}{c}\text { Sentimentos em } \\
\text { relação a Lula: }\end{array}$} & $\begin{array}{c}\text { Depois do } \\
\text { Debate }\end{array}$ & $\begin{array}{c}\text { Depois do } \\
\text { Dossiê }\end{array}$ & $\begin{array}{c}\text { Depois das } \\
\text { Fotos }\end{array}$ \\
\cline { 3 - 5 } & Ansiedade Lula & 0,008 & 0,128 & $-0,011$ \\
\hline \multirow{2}{*}{$\begin{array}{c}\text { Ruim/ Muito } \\
\text { Ruim }\end{array}$} & Entusiasmo Lula & 0,380 & 0,322 & 0,293 \\
\cline { 2 - 5 } & Ansiedade Lula & $\mathbf{0 , 3 1 7 ^ { * }}$ & $\mathbf{0 , 4 2 1 ^ { * }}$ & $\mathbf{0 , 3 8 4 ^ { * }}$ \\
\cline { 2 - 5 } & Entusiasmo Lula & $-0,085$ & $\mathbf{- 0 , 1 9 1 ^ { * * }}$ & $\mathbf{- 0 , 1 9 8 ^ { * * }}$ \\
\hline \multirow{2}{*}{$\begin{array}{c}\text { Boa/Muito } \\
\text { Boa }\end{array}$} & Ansiedade Lula & $\mathbf{0 , 6 4 0 ^ { * }}$ & $\mathbf{0 , 6 7 6 ^ { * }}$ & $\mathbf{0 , 6 1 8 ^ { * }}$ \\
\cline { 2 - 5 } & Entusiasmo Lula & $\mathbf{- 0 , 5 2 5 ^ { * }}$ & $\mathbf{- 0 , 5 3 3 ^ { * }}$ & $\mathbf{- 0 , 6 3 2 ^ { * }}$ \\
\hline
\end{tabular}

* correlação significativas até o nível de 0,01.

Fonte: Analítica Consultoria, Outubro de 2006

** correlação significativas até o nível de 0,05.

Esse modelo estabelece ainda que o sentimento de ansiedade atua de maneira indireta no voto. Nesse sentido, apesar de uma condição necessária para que haja uma mudança de voto, fatos que geram ansiedade no eleitorado não são determinantes para que governos bem avaliados percam a eleição. É necessário também que o(s) candidato(s) de oposição gere $(\mathrm{m})$ entusiasmo para que eleitores que avaliem bem determinado governo, mas que por algum motivo também são ansiosos em relação a ele, passem a votar nesse(s) candidato(s).

Assim, tal como mostra a Tabela 8, existem correlações positivas entre 0 sentimento de entusiasmo por Alckmin e o fato de os eleitores deixarem de votar em Lula depois dos eventos de curto prazo que geraram ansiedade. Além disso, observa-se que essas correlações são tão maiores quanto mais positiva a avaliação do governo Lula, o que denota que o sentimento de entusiasmo por Alckmin também é fundamental para explicar essa mudança no voto. 
PIMENTEL JUNIOR, T. J. Razão e emoção no voto: o voto na eleição presidencial de 2006.

Tabela 9

Avaliação do governo Lula, sentimentos por Alckmin e mudança no voto em Lula

\begin{tabular}{|c|c|c|c|c|}
\hline \multirow{2}{*}{$\begin{array}{c}\text { Avaliação } \\
\text { Governo Lula }\end{array}$} & $\begin{array}{c}\text { Sentimentos em relação } \\
\text { a Alckmin: }\end{array}$ & $\begin{array}{c}|c| \\
\text { Depois do } \\
\text { Debate }\end{array}$ & $\begin{array}{c}\text { Depois do } \\
\text { Dossiê }\end{array}$ & $\begin{array}{c}\text { Depois } \\
\text { das Fotos }\end{array}$ \\
\cline { 2 - 4 } $\begin{array}{c}\text { Ruim/ Muito } \\
\text { Ruim }\end{array}$ & Ansiedade Alckmin & 0,254 & 0,371 & 0,267 \\
\cline { 2 - 5 } & Entusiasmo Alckmin & $-0,235$ & $-0,161$ & $-0,226$ \\
\hline \multirow{2}{*}{\begin{tabular}{c} 
Regular \\
\cline { 2 - 5 }
\end{tabular}} & Ansiedade Alckmin & 0,105 & 0,117 & 0,123 \\
\hline \multirow{2}{*}{$\begin{array}{c}\text { Boa/Muito } \\
\text { Boa }\end{array}$} & Antusiasmo Alckmin & $\mathbf{0 , 2 1 4 *}$ & $\mathbf{0 , 2 7 9 *}$ & $\mathbf{0 , 2 6 3 *}$ \\
\cline { 2 - 5 } & Entusiasmo Alckmin & $\mathbf{0 , 5 4 9 *}$ & $\mathbf{0 , 2 0 8}$ & $-0,196$ \\
\hline
\end{tabular}

* correlação significativas até o nível de 0,01.

Fonte: Analítica Consultoria, Outubro de 2006.

Os dados mostram que os sentimentos positivos parecem estar correlacionados com a predisposição em votar em determinado candidato, enquanto a ansiedade afeta essa predisposição. Além disso, observou-se que o impacto da ansiedade no tempo de decisão e na mudança do voto é tanto maior quanto mais positiva é a avaliação do governo Lula.

A corroboração de nossas hipóteses nos leva a concluir que a aparente e clássica antítese entre razão e emoção pode constituir uma falácia, e aponta ainda para o fato de que o entendimento de um comportamento eleitoral considerado racional pela teoria econômica (mais especificamente, a teoria de voto retrospectivo) pode ser muito enriquecido pela consideração de que as emoções possuem um importante papel no processamento de informações políticas.

\section{Conclusões}

Partindo da ideia de interação entre razão e emoção, este artigo buscou demonstrar como as emoções podem ser tratadas teórica e empiricamente para se analisar comportamentos racionais. A partir do teste de hipóteses derivadas do modelo de Inteligência Afetiva pudemos observar que razão e emoção interagem na produção do comportamento eleitoral dos brasileiros.

O modelo de Inteligência Afetiva sugere que as emoções são anteriores a cognição dentro do processo de tomada de decisão e que dois sistemas afetivos engendram comportamentos racionais dos eleitores. O primeiro, o sistema de predisposição, ativa sentimentos de entusiasmo e leva os eleitores a se engajarem em seus hábitos ou aprenderem novos hábitos para a tomada de decisão. Já o segundo, o sistema de vigilância, ativa sentimentos de ansiedade que quebra essa 
tendência dos eleitores seguirem suas predisposições e ditam quando eles devem possuir considerações mais conscientes para a tomada de decisão.

O teste de nossas hipóteses mostrou que os sentimentos de entusiasmo estão correlacionados com a predisposição em votar em determinado candidato, enquanto a ansiedade afeta essa predisposição. Além disso, ficou demonstrado que os eleitores mais ansiosos possuem uma tendência em postergar a decisão eleitoral, refletindo melhor sobre sua predisposição em votar em dado candidato, e a mudar sua orientação de voto face a comportamentos reprováveis do governante, principalmente se acreditar que esse candidato à reeleição esteja desempenhando um bom governo.

Nossa análise possibilita entender melhor como a predisposição dos eleitores de votarem em Lula foi quebrada pelo sentimento de ansiedade gerado por fatores de curto prazo durante a campanha, mais especificamente pelo caso da compra do dossiê e seus desdobramentos, e aponta que é mais elucidativo explicar o comportamento eleitoral a partir da interação entre razão e emoção do que se os entendêssemos enquanto elementos antitéticos.

O estudo das emoções no comportamento eleitoral é fundamental para que possamos entender como os eleitores brasileiros decidem em quem votar. Este artigo buscou oferecer indícios disso e dar mais um passo nessa direção. Se através dele conseguirmos estabelecer um debate sobre o voto emocional, teremos alcançado esse objetivo.

\section{Referências Bibliográficas}

ARISTÓTELES. Arte retórica e arte poética. São Paulo: Difusão Europeia do Livro, 1959.

BABBIE, E. Métodos de Pesquisa em Survey. Belo Horizonte: Ed. UFMG, 2005. BRADER. T. Campaigning for hearts and minds. The University of Chicago Press, 2007.

HAIR, J. et al. Análise Multivariada de Dados. Ed. Bookman, 2005.

MAQUIAVEL, N. O Príncipe. São Paulo: Martins fontes, 2001.

MARCUS, G. The Psychology of Emotions and Politics. In: D., SEARS, D.; HUDDY, L.; JERVIS, R. (orgs.) Oxford Handbook of Political Psychology, Oxford, Oxford Univ.

Press, 2003. 
Chicago Press, 2000.

et al. Affective Intelligence and Political Judgment. Chicago: University of

PEREIRA, J. C. R. Análise de Dados Qualitativos. São Paulo: EDUSP, 2004.

ROSEMAN, I. J. "Cognitive Determinants of Emotions: A Structural Theory". In: P. SHAVER (Ed.). Review of Personality and Social Psychology (vol. 5), 11-36, Beverly Hills, CA: Sage, 1984.

SCHWARTZENBERG, R. O Estado espetáculo. Rio de Janeiro: Difusão, 1978.

SILVEIRA, F. E. A Decisão do Voto no Brasil. Porto Alegre: EDIPUCRS, 2000.

SULLIVAN, D. \& MASTER, R. "Gut Reactions and the Political Effects of the Media", PS, vol. 20, nº. 04, 1987.

TORANGEAU,R. et al. The Psychology of Survey Response. New York: Cambridge University Press, 2000.

WEBER, M. Economia e Sociedade. vol. 1, Brasília: Ed. Universidade de Brasília, 1991.

WESTEN, D. The Political Brain. Public Affairs, 2007.

ZAJONC, R. B. "Feeling and thinking. Preferences need no inferences." American Psychologist, 35 (2), p.151-175, 1980.

1984. . "On the Primacy of Affect". American Psychologist, vol. 39, p.117.23,

Jairo Tadeu Pires Pimentel Junior - jairopimentel@usp.br

Recebido para publicação em julho 2009.

Aprovado para publicação em julho 2010. 